\title{
The d-q Modeling, Order Reduction and Numerical Analysis of Double Cage Three Phase Induction Machine for Power System Studies
}

\author{
Sudhir Kumar, P. K. Ghosh and S. Mukherjee
}

\begin{abstract}
The study of induction machine is becoming important in power system dynamic analysis. An accurate algorithm for determining induction machine transients is presented here. Higher order model of double cage induction machine is simplified and solved using Runge-Kutta, Trapezoidal and Euler's methods in Mat-lab platform. The authors compute the rotor speed versus time profile, stator current and stator flux linkage for various load conditions and supply voltage disturbances using the concept of the speed-build up of induction machines. The 7th order model of a double cage induction machine has been reduced here to a 5 th order model with a structure different from the regular 5th order model for single cage induction machine. Model Order Reduction (MOR) incorporates a set of techniques aiming at generating reduced order models with lower complexity while ensuring the I/O response and other characteristics of the original model (such as passivity). To obtain stability in digital simulation, winding flux-linkages are used as state variables in contrast to current flow. Comparison of computational times in the reported three methods is made. We have verified less computation time in reduced order models and an improvement in the accuracy is also observed.
\end{abstract}

Index Terms - Induction machine, Order reduction, Stability, Transient analysis, Power System

\section{INTRODUCTION}

The squirrel cage induction machine drives in power systems are regarded as the state of the art of industrial variable speed applications. They represent the best solution for the substitution of dc machine drives which require thorough and expensive maintenance. The modeling of complex dynamic systems is one of the most important subjects in the field of engineering. A model sometimes happens to be too complicated to be useful in real problems. So, approximation procedures based on physical considerations or mathematical approaches are used to obtain simpler models of the original one. The subject of model reduction is very important and relevant to engineers and scientists working in many fields of engineering, especially, for those who work in the area of process control and power systems. Effort towards obtaining lower order models from higher order model systems aims at deriving stable reduced

Manuscript received on November 15, 2010 for review.

Sudhir Kumar and P. K. Ghosh are with Faculty of Engineering and Technology, Mody Institute of Technology and Science (Deemed University), Lakshmangarh-332 311, Distt. Sikar, (Rajasthan), India. (Fax: +91-1573-225042; email:skumar_icfai@yahoo.co.in;pkghosh_ece@yahoo.c o.in).

S. Mukherjee is with the Department of Electrical Engineering, Indian Institute of Technology Roorkee, Uttrakhand, India.(email: mukherjee.shaktidev@gmail.com). order models from the stable original ones and assuring that the reduced order model matches some quantities of original one. The past three decades have witnessed many researches in state space and transfer function forms towards these two objectives [1-31]. Further, high power induction motors have found increasing use in recent years. In order to limit the starting current and to have a reasonably large starting torque, these motors are generally equipped with a double-cage or deep-bar rotor. In this paper, the machine models are developed for a double-cage induction machine. The resulting models can be applied with some degree of approximation to induction machines with deep-bar rotor as well. This is because an equivalent double-cage machine can always be found with an admittance locus closely fitting to that of a deep-bar induction machine [18].

Modeling each poly-phase winding effectively as second-order $\mathrm{d}-\mathrm{q}$ equation in the generalized theory of electrical machines, the transient model of a double cage induction machine comes out a seventh-order with six electrical variables and one mechanical variable, i.e. motor speed, as state variables. But, the complete representation of induction motors in the literature [18-20] is usually described by a fifth-order model whereas it is generally accepted to include induction machine models in certain power system studies [22-25]. However, in those cases it is worth considering that, the induction motors are usually of the larger size. The fifth-order model or its derivatives to represent these large machines would generally ignore the presence of the second rotor cage winding. It should be noted that for the transient stability studies in power systems, it has become customary to use a simplified version of this fifth-order model by neglecting stator flux transients.

The importance of the starting cage of high power motors in system analysis has been worked out in the research papers [28-29] in which order reduction of the complete seventh-order model were achieved by neglecting stator transients. Consequently, they have neglected the speed voltages in both rotor windings incorrectly resulting in a poor agreement of the speed behavior as compared to that of the full-order model. Moreover, the results would only be applicable in cases where high frequency components in the power flow are not of interest such as in transient stability studies.

In this study, we will show that the full-order model of an induction motor with double-cage rotor can be readily reduced to a fifth-order model while practically retaining the instantaneous behavior of the rotor speed, stator current and stator flux linkage at the machine terminals. The organization 
of this paper is as follows. Section II describes the analytical details of full order machine model. The reduced order machine model is detailed in section III. The resulting equations neglecting faster transients are also derived. The methodology for machine order reduction is presented with flow chart diagram in Fig.1 of section IV. Section V portrays numerical results and discussions by using Runge-Kutta, Trapezoidal and Euler's methods in Matlab platform. Finally, we conclude in section VI.

\section{Full ORDER MACHINE MOdEL}

For the modeling of induction machines, we choose the flux linkage as the state variable. Flux linkages are used since in the digital simulation of the model, the variables provide more stability with the same integration time step. Equivalently, a larger time step can be used to obtain the same accuracy; thus requiring less computational time.

This is the fact that flux linkages of electromagnetically coupled circuits cannot change instantaneously, whereas circuit currents which make up the flux linkages can relatively change slowly rather than abruptly in cases where the circuits are singly fed, such as considered here. This is particularly true if the fast transients due to an electromagnetically coupled circuit are neglected and computational instability can even occur which has been observed in the simulation studies.

Following the aforesaid assumptions as in the generalized theory of electrical machines [26] and using a synchronously rotating reference frame, the electrical equations in complex form for the stator, inner and outer cage windings are respectively given by

$$
\begin{aligned}
& v_{1}=i_{1} r_{1}+j \omega \psi_{1}+\frac{d \psi_{1}}{d t} \\
& 0=i_{2} r_{2}+j \omega \psi_{2}+\frac{d \psi_{2}}{d t} \\
& 0=i_{3} r_{3}+j \omega \psi_{3}+\frac{d \psi_{3}}{d t}
\end{aligned}
$$

where, the voltage (v), currents (i) and flux-linkages $(\Psi)$ are time dependent complex variables and related to the real $\mathrm{d}-\mathrm{q}$ variables by

$$
f=f_{d}-j f_{q} .
$$

Here, f represents a voltage, current or flux-linkage. Employing the per-unit system with equal per-unit mutual inductances between the three windings on each axis, the inductance matrix L given by

$$
\psi=L i
$$

can be written as

$$
L=\left[\begin{array}{ccc}
l_{m}+l_{1} & l_{m} & l_{m} \\
l_{m} & l_{m}+l_{2} & l_{m} \\
l_{m} & l_{m} & l_{m}+l_{3}
\end{array}\right]
$$

Thus the current in matrix form can be written as

$$
i=L^{-1} \psi f
$$

with

$$
L^{-1}=\frac{1}{i}\left[\begin{array}{ccc}
l_{11} & -l_{3} l_{m} & -l_{2} l_{m} \\
l_{3} l_{m} & l_{22} & -l_{1} l_{m} \\
-l_{2} l_{m} & -l_{1} l_{m} & l_{38}
\end{array}\right]
$$

where,

$$
\begin{gathered}
l_{11}=l_{2} l_{3}+l_{2} l_{m}+l_{2} l_{m} \\
l_{22}=l_{1} l_{3}+l_{1} l_{m}+l_{3} l_{m} \\
l_{33}=l_{1} l_{2}+l_{1} l_{m}+l_{2} l_{m} \\
l=l_{1} l_{2} l_{3}+l_{1} l_{2} l_{m}+l_{1} l_{3} l_{m}+l_{2} l_{3} l_{m} .
\end{gathered}
$$

Substitution of (5) in (1) gives the machine equations in state-variable from as

$$
\begin{aligned}
& \frac{d \psi_{1}}{d t}=\left[\left(\frac{r_{1} l_{11}}{l}\right)+j \omega\right] \psi_{1}+\left(\frac{r_{1} l_{3} l_{m}}{l}\right) \psi_{2}+\left(\frac{r_{1} l_{2} l_{m}}{l}\right) \psi_{3}+v \\
& \frac{d \psi_{2}}{d t}=\left[\left(\frac{r_{2} l_{3} l_{m}}{l}\right) \psi_{1}-\left[\left(\frac{r_{2} l_{22}}{l}\right)+j s \omega\right] \psi_{2}+\left(\frac{r_{2} l_{1} l_{m}}{l}\right) \psi_{3}\right] \\
& \frac{d \psi_{3}}{d t}=\left[\left(\frac{r_{3} l_{2} l_{m}}{l}\right) \psi_{1}+\left(\frac{r_{3} l_{1} l_{m}}{l}\right) \psi_{2}-\left[\left(\frac{r_{3} l_{33}}{l}\right)+j s \omega\right] \psi_{3}\right.
\end{aligned}
$$

The equations dealing the mechanical motion in per-unit are given as

$$
\frac{d s}{d t}=-\left(\frac{1}{2 H \omega}\right)\left(t e-t_{l}\right)
$$

where, $t_{\theta}=\operatorname{Im}\left(\psi^{8}{ }_{1}{ }_{1}\right)$ which can be written with the help of (5) as

$$
t_{e}=\left(\frac{l_{m}}{l}\right) \operatorname{Im}\left\{l_{3} \psi_{1} \psi_{2}^{*}+l_{2} \psi_{1} \psi_{3}^{*}\right\}
$$

For digital simulation, the complex variables in (8) and (10) are resolved into their real d-q components as expressed by (2) resulting in

$$
\frac{d \psi_{1 d}}{d t}=-\left(\frac{r_{1} l_{11}}{l}\right) \psi_{1 d}-\omega \psi_{1 q}+\left(\frac{r_{1} l_{3} l_{m}}{l}\right) \psi_{2 d}+\left(\frac{r_{1} l_{2} l_{m}}{l}\right) \psi_{3 d}+v_{d}
$$

$$
\begin{aligned}
& \frac{d \psi_{1 q}}{d t}=\omega \psi_{1 d}-\left(\frac{r_{1} l_{11}}{l}\right) \psi_{1 q}+\left(\frac{r_{1} l_{3} l_{m}}{l}\right) \psi_{2 q}+\left(\frac{r_{1} l_{2} l_{m}}{l}\right) \psi_{3 q}+v_{q} \\
& \frac{d \psi_{2 d}}{d t}=\left(\frac{r_{2} l_{3} l_{m}}{l}\right) \psi_{1 d}-\left(\frac{r_{2} l_{22}}{l}\right) \psi_{2 d}-s \omega \psi_{2 q}+\left(\frac{r_{2} l_{1} l_{m}}{l}\right) \psi_{3 d}
\end{aligned}
$$$$
\frac{d \psi_{2 q}}{d t}=\left(\frac{r_{2} l_{3} l_{m}}{l}\right) \psi_{1 d}+s \omega \psi_{2 d}-\left(\frac{r_{2} l_{22}}{l}\right) \psi_{2 q}+\left(\frac{r_{2} l_{1} l_{m}}{l}\right) \psi_{3 q}
$$$$
\frac{d \psi_{3 d}}{d t}=-\left(\frac{r_{3} l_{2} l_{m}}{l}\right) \psi_{1 d}+\left(\frac{r_{3} l_{1} l_{m}}{l}\right) \psi_{2 d}-\left(\frac{r_{3} l_{33}}{l}\right) \psi_{3 d}-s \omega \psi_{3 q}
$$$$
\frac{d \psi_{3 q}}{d t}=\left(\frac{r_{3} l_{2} l_{m}}{l}\right) \psi_{1 q}+\left(\frac{r_{3} l_{1} l_{m}}{l}\right) \psi_{2 q}+s \omega \psi_{3 d}-\left(\frac{r_{3} l_{33}}{l}\right) \psi_{3 q}
$$ 


$$
\begin{aligned}
& \frac{d s}{d t}=-\left(\frac{1}{2 H \omega}\right)\left[\left(\frac{l_{2} l_{m}}{l}\right) \psi_{1 d} \psi_{2 q}-\left(\frac{l_{3} l_{m}}{l}\right) \psi_{1 q} \psi_{2 d}+\left(\frac{l_{2} l_{m}}{l}\right) \psi_{1 d} \psi_{3 q}\right. \\
& -\left(\frac{l_{2} l_{m}}{l}\right) \psi_{1 q} \psi_{3 d}-t_{l}
\end{aligned}
$$

The phase voltages $\mathrm{V}_{\mathrm{a}}, \mathrm{V}_{\mathrm{b}}$ and $\mathrm{V}_{\mathrm{c}}$ in matrix form becomes

$$
\left[\begin{array}{l}
V_{a} \\
V_{b} \\
V_{c}
\end{array}\right]=V_{m}\left[\begin{array}{c}
\sin \theta \\
\sin (\theta-2 \pi / 3) \\
\sin [\theta+2 \pi / 3]
\end{array}\right]
$$

\section{REDUCED ORDER MACHINE MODEL}

\section{A. Neglecting Faster Transients}

This is a normal practice that the outer cage of double-cage induction motor is generally designed to give a limited starting current with a relatively large starting torque. This is accomplished by making the resistance and leakage inductance of the outer (starting) cage higher and lower, respectively than the corresponding parameter of the inner (running) cage resulting in $\mathrm{r}_{3}>>\mathrm{r}_{2}$ and $\mathrm{l}_{3}<\mathrm{l}_{2}$.

A close look into the transient behavior caused by the presence of the two cages is going through by comparing the two time constants of the equivalent rotor winding, $\tau_{2}=l_{2} / \mathbf{r}_{2}$ and $\tau_{3}=1_{3} / r_{3}$. Since $\tau_{3}<<\tau_{2}$, the transients associated with the outer cage are much faster than those with the inner cage, as confirmed by an eigen-value analysis [23].

The order-reduction of the motor model is obtained by neglecting the fast transients due to the outer cage. This amounts to setting the derivative of flux-linkage $\Psi_{3}$ of the outer cage in the differential equations equal to zero so that $\Psi_{3}$ can be algebraically expressed in terms of the other flux-linkages. This value when substituted in the remaining differential equations reduces the system order.

\section{B. Fifth-Order Model}

Following the procedure outlined in the preceding section, setting $\mathrm{d}_{3} / \mathrm{dt}=0$ in the last equation of (8) provides

$$
\Psi_{3}=\frac{\frac{l_{2} l_{3}}{l_{33}}\left(1-j s^{\prime}\right) \Psi_{1}+\frac{l_{1} l_{m}}{l_{32}}\left(1-j s^{\prime}\right) \Psi_{2}}{1+s^{2}}
$$

where,

$$
s^{1}=\left(\omega l / r_{3} l_{33}\right) s
$$

Substitution of this expression in the first two equations of (8) and in (9) yields the reduced order form of the machine model.

$$
\begin{aligned}
& \frac{d \psi_{1}}{d t}=\left[\left(R_{11}+j L_{11}\right) \psi_{1}+\left(R_{12}+j L_{12}\right) \psi_{2}+v\right] \\
& \frac{d \psi_{2}}{d t}=\left[\left(R_{21}+j L_{21}\right) \psi_{1}+\left(R_{22}+j L_{22}\right) \psi_{2}\right]
\end{aligned}
$$

$\frac{d s^{\prime}}{d t}=\left(\frac{1}{2 H \omega}\right)\left[\left(\frac{\omega}{r_{1} r_{3} l_{33}}\right) \operatorname{Im}\left\{\left(R_{12}-j L_{12}\right) \psi_{1} \psi_{2}^{*}\right\}-\left(\frac{\omega l_{2}}{r_{1} r_{3} l_{1} l_{33}}\right) L_{12} \psi_{1}^{2}\right.$ $\left.-t_{l}^{\prime}\right]$

with

$\mathrm{R}_{11}=-\left(\mathrm{r}_{1} \mathrm{l}_{11} / \mathrm{l}\right)+\left(\mathrm{r}_{1} \mathrm{l}_{2}^{2} \mathrm{l}_{\mathrm{m}}^{2} / 1 \mathrm{l}_{33}\right) /\left(1+\mathrm{s}^{/ 2}\right)$

$\mathrm{R}_{22}=-\left(\mathrm{r}_{2} \mathrm{l}_{22} / \mathrm{l}\right)+\left(\mathrm{r}_{2} \mathrm{l}_{1}{ }^{1} \mathrm{l}_{\mathrm{m}}{ }^{2} / \mathrm{ll}_{33}\right) /\left(1+\mathrm{s}^{2}\right)$

$\mathrm{R}_{12}=\left(\mathrm{r}_{1} \mathrm{l}_{3} \mathrm{l}_{\mathrm{m}} / \mathrm{l}\right)+\left(\mathrm{r}_{1} \mathrm{l}_{1} \mathrm{l}_{2} \mathrm{l}_{\mathrm{m}}{ }^{2} / \mathrm{l}_{33}\right) /\left(1+\mathrm{s}^{\prime 2}\right)$

$\mathrm{R}_{21}=\left(\mathrm{r}_{2} / \mathrm{r}_{1}\right) \mathrm{R}_{12}$

$\mathrm{L}_{11}=-\omega-\left(\mathrm{r}_{1} \mathrm{l}_{2}{ }^{2} \mathrm{l}_{\mathrm{m}}{ }^{2} / \mathrm{ll}_{33}\right) /\left(1+\mathrm{s}^{\prime 2}\right)$

$\mathrm{L}_{22}=-\left(\mathrm{r}_{3} \mathrm{l}_{33} / \mathrm{l}\right) \mathrm{s}^{\prime}-\left(\mathrm{r}_{2} \mathrm{l}_{1}{ }^{2} \mathrm{l}_{\mathrm{m}}^{2} / \mathrm{ll}_{33}\right) \mathrm{s}^{\prime} /\left(1+\mathrm{s}^{\prime 2}\right)$

$\mathrm{L}_{12}=-\left(\mathrm{r}_{1} \mathrm{l}_{1} \mathrm{l}_{2} \mathrm{l}_{\mathrm{m}}{ }^{2} / \mathrm{ll}_{33}\right) \mathrm{s}^{\prime} /\left(1+\mathrm{s}^{\prime 2}\right)$

$\mathrm{L}_{21}=\left(\mathrm{r}_{2} / \mathrm{r}_{1}\right) \mathrm{L}_{12}$

$t_{1}^{\prime}=\left(\omega 1 / r_{3} l_{33}\right) t_{1}$

This reduced order model holds for any value of motor speed since the basis for it, as seen from the eigen value analysis, is valid for the entire range of motor speed.

For digital simulation purposes, the equations are written in the real form

$$
\begin{aligned}
& \frac{d \Psi_{1 d}}{d t}=R_{11} \Psi_{1 d}+L_{11} \Psi_{1 Q}+R_{12} \Psi_{2 d}+R_{12} \Psi_{2 Q}+V_{d} \\
& \frac{d \Psi_{1 Q}}{d t}=L_{11} \Psi_{1 d}+R_{11} \Psi_{1 Q}-L_{12} \Psi_{2 d}+R_{12} \Psi_{2 Q}+V_{Q} \\
& \frac{d \Psi_{2 d}}{d t}=R_{21} \Psi_{1 d}+L_{21} \Psi_{1 Q}+R_{22} \Psi_{2 d}+R_{22} \Psi_{2 Q} \\
& \frac{d \Psi_{2 q}}{d t}=-L_{21} \Psi_{1 d}+R_{21} \Psi_{1 Q}-L_{22} \Psi_{2 d}+R_{22} \Psi_{2 Q} \\
& \frac{d s^{\prime}}{d t}=-\left(\frac{1}{2 R \omega}\right)\left[\left(\frac{\omega l}{r_{12} l_{2 a}}\right) R_{12}\left(\Psi_{1 d} \Psi_{2 q}-\Psi_{10} \Psi_{2 d}\right)-\right. \\
& \left(\frac{\omega l}{w_{12} h_{22}}\right) L_{12}\left(\Psi_{1 d} \Psi_{2 d}+\Psi_{1 q} \Psi_{2 q}\right)- \\
& \left.\left(\frac{\omega l_{2}^{2}}{w_{1} r_{3} l_{38}}\right) L_{12}\left(\Psi_{1 d}^{2}+\Psi_{10}^{2}\right)-t_{1}^{\prime}\right]
\end{aligned}
$$

The symbols of the above equations are defined in appendix of this paper.

It is to be noted that the reduced order model (18) and the conventional complete model for a single-cage motor are of the same order; but their structures are quite different so that no parameter values for the conventional fifth-order model can be found which provide the same transient behavior as in the double-cage motor. 
IV. Methodology For Machine ORder REduction

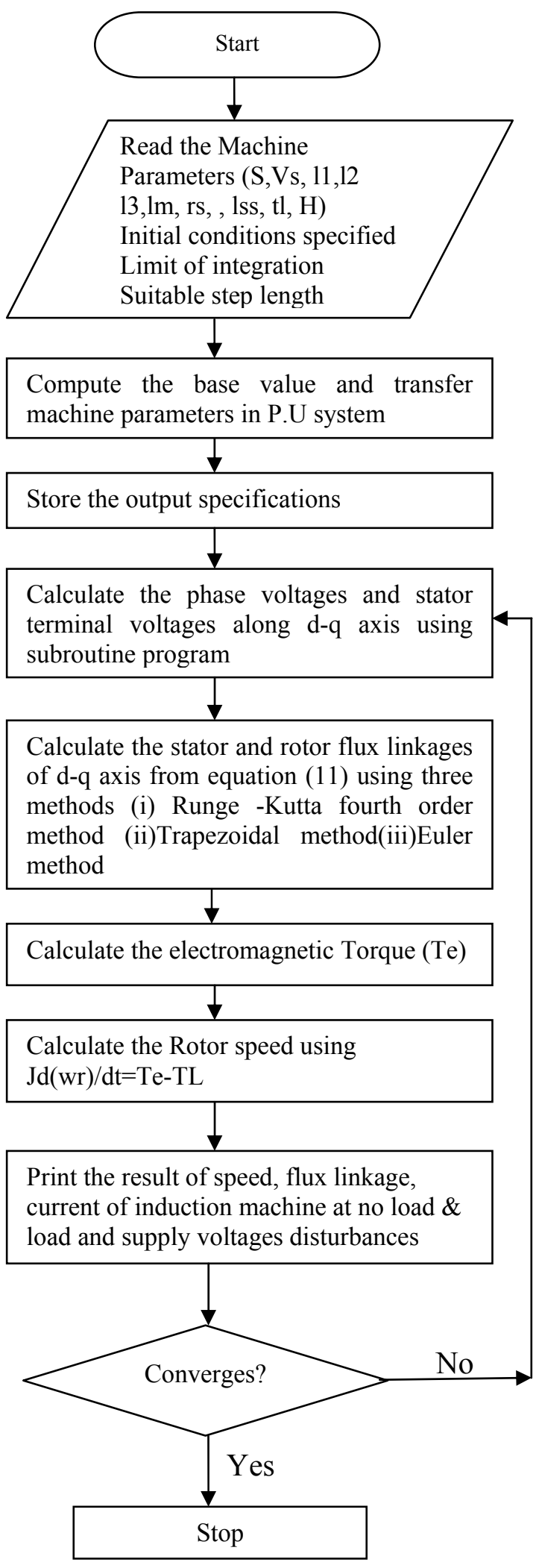

Figure 1: Flow chart of simulation algorithm

\section{RESUltS AND DisCUSSIONS}

The reduced order model of double cage induction machine developed was validated by digital simulation and comparison with the response of full order model. The reduced order model is applied to a $4500 \mathrm{HP}, 2900 \mathrm{rpm}$,
$6.6 \mathrm{Kv}, 50 \mathrm{~Hz}$ double cage induction machine and its performance characteristics for stator current, stator flux-linkage and rotor speed are obtained as shown in figures 2(a-c) and 3(a-c) under load and no-load torque disturbances, and supply voltage variations. The results are compared with the full order model. The performance characteristic of reduced order model comes out to be almost identical to that of full order model of double cage induction machine. The machine parameters for double cage induction machine under analysis are given in Table I.

The suitable numerical techniques; Runge-Kutta, Trapezoidal' $\mathrm{s}$ and Euler's methods are used to solve the non-linear differential equations to integrate the differential equation with an integration size of 0.001 . The computational time obtained for full order and reduced order models using three numerical methods are also compared in table II. The algorithm presented in this paper introduces a considerable advantage in computational speed as indicated by comparative results given in the table II.

TABLE I. SPECIFICATION AND MACHINE PARAMETERS OF DOUBLE CAGE INDUCTION MACHINE

$4500 \mathrm{HP}, 2900 \mathrm{RPM}, 6.6 \mathrm{KV}, 50 \mathrm{~Hz}, \mathrm{THREE}$ PHASE INDUCTION MACHINE

\begin{tabular}{|l|l|}
\hline Machine Parameter & P.U. Value \\
\hline Stator resistance $\left(\mathrm{r}_{1}\right)$ & $7.4 \times 10^{-3}$ \\
\hline Inner cage winding resistance $\left(\mathrm{r}_{2}\right)$ & $7.27 \times 10^{-3}$ \\
\hline Outer cage winding resistance $\left(\mathrm{r}_{3}\right)$ & $7.36 \times 10^{-3}$ \\
\hline Stator inductance $\left(1_{1}\right)$ & $3.47 \times 10^{-4}$ \\
\hline Inner cage inductances $\left(\mathrm{l}_{2}\right)$ & $3.58 \times 10^{-4}$ \\
\hline Outer cage inductances $\left(1_{3}\right)$ & $3.63 \times 10^{-4}$ \\
\hline Magnestising inductances $\left(\mathrm{l}_{\mathrm{m}}\right)$ & 0.0115 \\
\hline Inertia constant $(\mathrm{h})$ & $2 \mathrm{sec}$ \\
\hline
\end{tabular}

TABLE II. COMPARISON OF COMPUTATIONAL TIME OBTAINED FOR FULL ORder AND REDUCED ORder MODELS IN THREE NuMERICAL METHOdS USING MATLAB

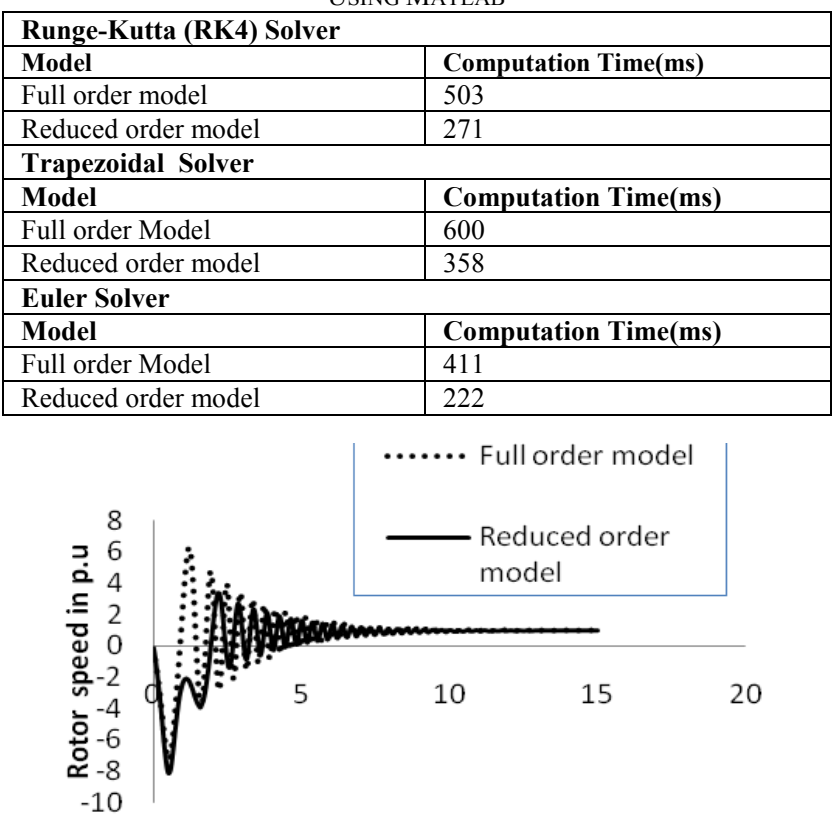

Time in sec

Figure: 2 (a) 

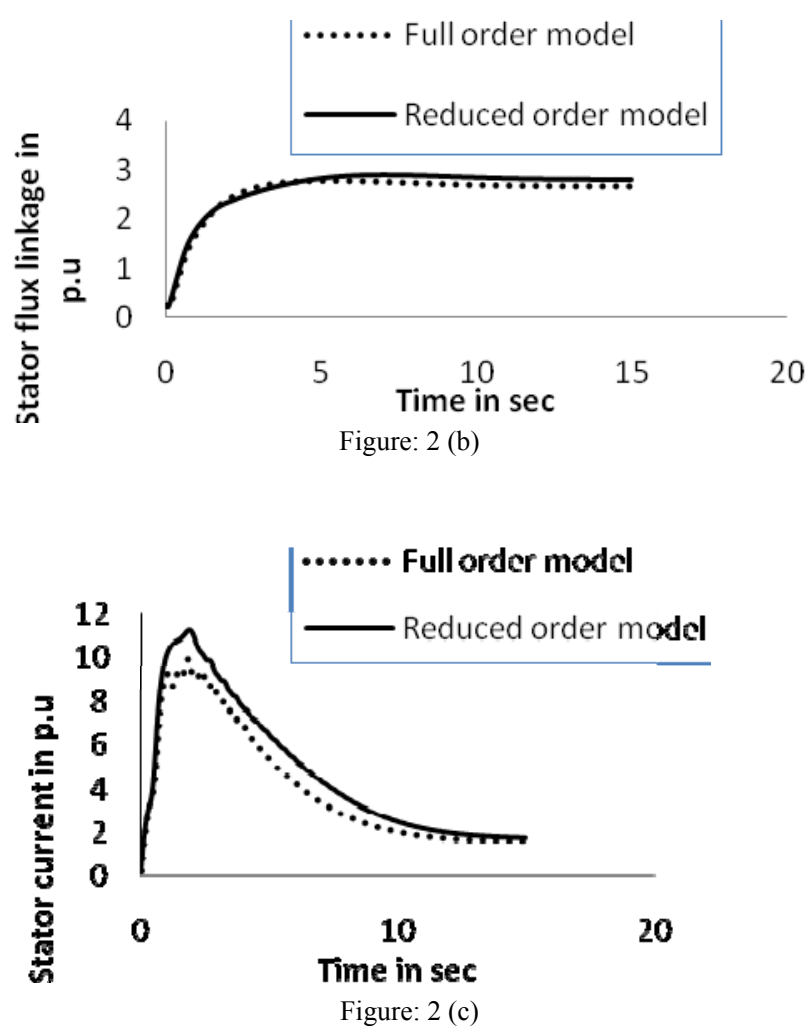

Fig2 (a-c): Response of Full order Model \& Reduced order model under load condition and supply voltage changes $(15 \%)$

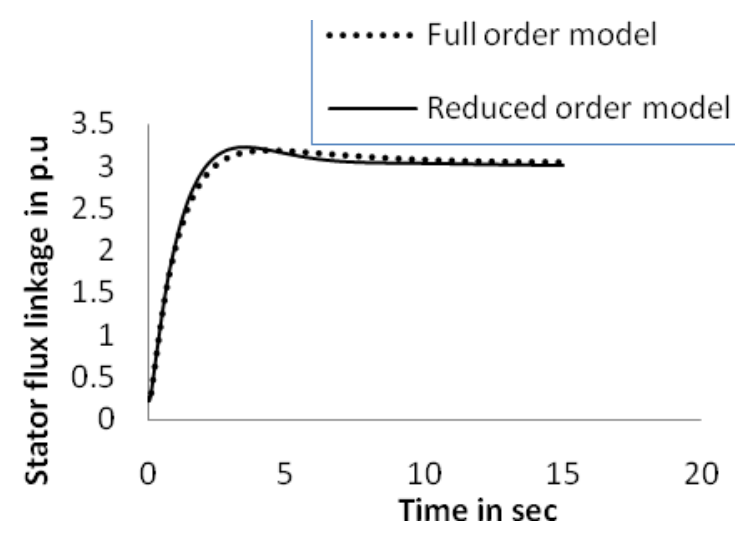

Figure: 3 (a)

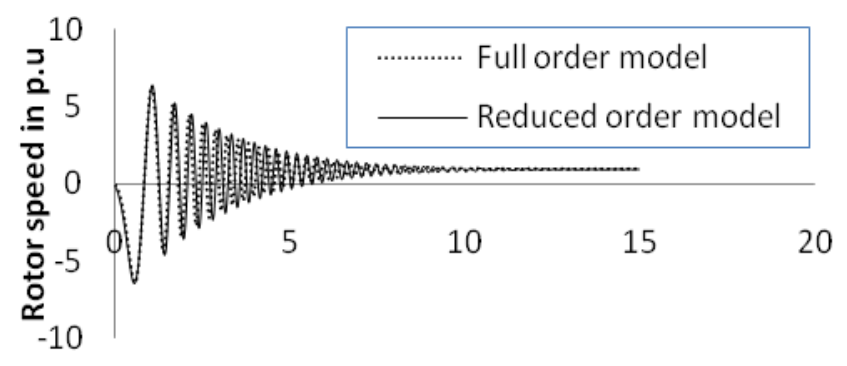

Time in sec

Figure:3 (b)

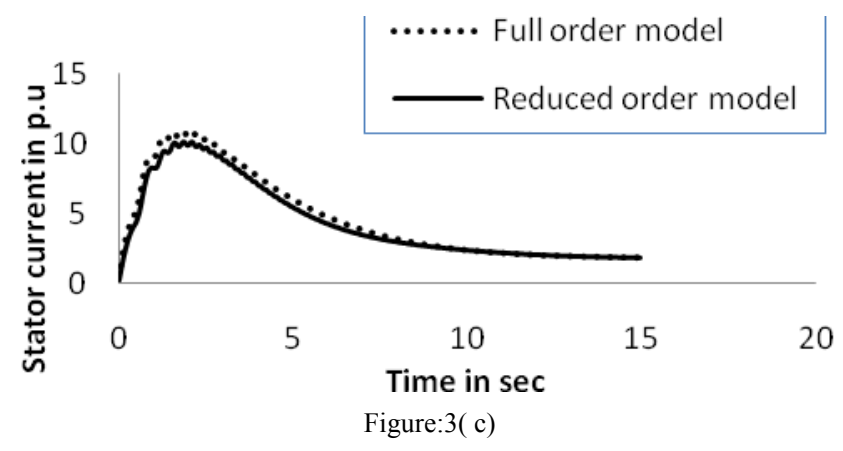

Figure 3(a-c): Response of Full Order Model \& Reduced order Model under no load condition and at rated supply voltage

\section{CONCLUSION}

The simulation results show that the fifth order model is almost identical with the complete seventh order model. The reduced order model can also be used for computing the induction machine contribution to initial power system fault currents including dc offsets, and in selecting and coordinating protective devices. In short, the fifth-order machine model can be substitute for the seventh-order model in power system for any simulation kind of study. The computational times of the system using three numerical methods due to Runge-Kutta, Trapezoidal and Euler have been compared and significant reduction in computation time has been observed.

\section{APPENDIX}

1,2,3 Subscripts referring to stator, running (inner) and starting (outer) cage windings, respectively.

$\mathrm{d}, \mathrm{q} \quad$ Subscript referring to $\mathrm{d}$ and $\mathrm{q}$ axis.

j Imaginary unit.

* Superscripts referring to complex conjugates.

$\omega \quad$ Angular frequency of power supply in radian per sec.

v Terminal voltage of stator winding.

$\mathrm{R}_{\mathrm{j}} \quad$ Resistance of winding $\mathrm{j}$.

$1_{1}, l_{2}, l_{3} \quad$ Leakage reactance of stator, inner and outer cage windings, respectively.

$1_{\mathrm{m}} \quad$ Magnetizing inductance in per unit.

$\mathrm{S} \quad$ Motor slip.

$\omega_{\mathrm{e}} \quad$ Angular motor speed in electrical radian per sec.

$t_{e}, t_{1} \quad$ Motor and load torque in per unit.

$\mathrm{H} \quad$ Inertia Constant of motor and load in second.

\section{ACKNOWLEDGMENT}

Sudhir Kumar sincerely acknowledges the valuable discussions made with Prof. (Dr.) A. B. Chattopadhyay, Birla Institute of Technology and Science, Pilani (Rajasthan) Dubai campus, and Professor V. P. Shukla, Mody Institute of Technology and Science, Lakshmangarh, Sikar (Rajasthan) India.

\section{REFERENCES}

[1] R. Genesio and M. Milanese, "A note on the derivation and use of reduced order models", IEEE Trans. Automat. Control, Vol. AC-21,No. 1, pp. 118-122, February 1976. 
[2] M. S. Mahmoud and M. G. Singh, Large Scale Systems Modelling, Pergamon Press, International Series on Systems and Control 1st ed.,Vol. 3, 1981.

[3] M. Jamshidi, Large Scale Systems Modelling and Control Series, New York, Amsterdam, Oxford, North Holland, Vol. 9, 1983.

[4] S. K. Nagar and S. K. Singh, "An algorithmic approach for system decomposition and balanced realized model reduction", Journal of Franklin Inst., Vol. 341, pp. 615-630, 2004.

[5] V. Singh, D. Chandra and H. Kar, "Improved Routh Pade approximants:A computer aided approach", IEEE Trans. Automat. Control, Vol. 49, No.2, pp 292-296, February 2004.

[6] S. Mukherjee, Satakshi and R.C.Mittal, "Model order reduction using response-matching technique", Journal of Franklin Inst., Vol. 342 , pp. 503-519, 2005 .

[7] B. Salimbahrami, and B. Lohmann, "Order reduction of large scale second-order systems using Krylov subspace methods", Linear Algebra Appl., Vol. 415, pp. 385-405, 2006.

[8] S. Mukherjee and R.N. Mishra, "Reduced order modelling of linear multivariable systems using an error minimization technique", Journal of Franklin Inst., Vol. 325, No. 2 , pp. 235-245, 1988.

[9] S. S. Lamba, R. Gorez and B. Bandyopadhyay, "New reduction technique by step error minimization for multivariable systems", Int J.Systems Sci., Vol. 19, No. 6, pp. 999-1009, 1988.

[10] R. Prasad and J. Pal, "Use of continued fraction expansion for stable reduction of linear multivariable systems", Journal of Institution of Engineers, India, IE(I) Journal - EL, Vol. 72, pp. 43-47, June 1991.

[11] R. Prasad, A. K. Mittal and S. P. Sharma, "A mixed method for the reduction of multi-variable systems", Journal of Institution of Engineers,India, IE(I) Journal - EL, Vol. 85, pp. 177-181, March 2005.

[12] T.C. Chen, C.Y. Chang and K.W. Han, "Reduction of transfer functions by the stability equation method", Journal of Franklin Inst., Vol. 308, No. 4, pp. 389-404, 1979.

[13] T.C. Chen, C.Y. Chang and K.W. Han, "Model reduction using the stability equation method and the continued fraction method", Int. J. Control, Vol. 32, No. 1, pp. 81-94, 1980.

[14] C.P. Therapos, "Stability equation method to reduce the order of fast oscillating systems", Electronic Letters, Vol. 19, No.5, pp.183-184, March 1983.

[15] T.C. Chen, C.Y. Chang and K.W. Han, "Stable reduced order Pade approximants using stability equation method", Electronic Letters, Vol. 16, No. 9, pp. 345-346, 1980.

[16] J. Pal, "Improved Pade approximants using stability equation method",Electronic Letters, Vol. 19, No.11, pp.426-427, May 1983.

[17] R. Parthasarathy and K.N. Jayasimha, "System reduction using stabilityequation method and modified Cauer continued fraction", ProceedingsIEEE, Vol. 70, No. 10, pp.1234-1236, October 1982.

[18] G. G. Richard and O.T.Tan "Simplified model for induction machine transients under Balanced \& unbalanced condition", IEEE Trans. on industrial Application, Jan /Feb 1981.

[19] F.D.Radrigas and O.Waaynaxuk, "A method of representing isolated operation of Group of induction motor loads", IEEE Trans. on power systems, Vol. PWRS-2, No.3, pp. 568-575, August, 1987.

[20] Stag \& EI-Abiad, Computer method in power system analysis, 1968. International student edition.

[21] G.G Richard, "Reduced order model for an induction motor group during Bus-Transfer", IEEE Trans. on power system, Vol.1, No. 2 pp. 494-498, May 1989.

[22] T.L. Savanna and P.C. Krause, "Accuracy of a Reduced order model of induction machine in dynamo-stability studies", IEEE Trans. on AC power app. \& system, Vol. PAS-98, No. 4, pp. 1192-1197, July/Aug 1979.

[23] S.Ertem andY.Baghzouz, "Simulation of induction machinery for power system studies", IEEE Trans. on Energy conversion, Vol- 4, No. 1, March 1989.

[24] D. Wasynvzuk, Y.Diao \&P.C. Krause, "Theory and comparison of reduced - order model of induction machines", IEEE Trans. power apparatus \& system, Vol. PAS 104, No.3, pp. 598-606, March 1985.

[25] D.G Shultz \& J.L. Melsa, State function and linear control system, Mc-Graw Hill ,1957

[26] B. Adkins and R.Harley, The general Theory of Alternating Current Machine: Application to practical problems. London, Chapman and Hall, 1975
[27] P.C Krause and C.H Thomas, "Simulation of Electrical Machinery", IEEE Trans. Power Appratus and Systems, Vol..PAS-86, pp.1038-1053, Nov 1965.

[28] G.G. Richards and O.T Tan, "Decomposed, Reduced order Model for Double cage induction Machine", IEEE Trans. on Energy conversion, Vol. EC-1. No.3, pp. 87-93, Sep. 1986.

[29] N.A. Kh N.A. Khalil, O.T Tan, I.U Baran. "Reduced order model for double cage induction machines", IEEE Trans. power apparatus and System, Vol. PAS-101, No.9, pp. 3135.39, Sept. 1982.

[30] G. Parmar, S. Mukherjee and R. Prasad, "System reduction using factor division algorithm and eigen spectrum analysis", Applied Mathematical Modelling, Elsevier, Vol. 31, pp 2542-2552, 2007.

[31] G. Parmar, S. Mukherjee and R. Prasad, "Reduced order modelling of linear MIMO systems using Genetic Algorithm", Int. Journal of Simulation Modelling, Vol. 6, No. 3, pp. 173-184, 2007.

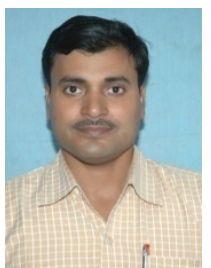

Sudhir Kumar was born in Patna, India in 1974 $\mathrm{He}$ received his B. Tech in Electrical and Electronics Engineering from Bangalore university in 1996 and M. Tech in Electrical Power Systems Engineering from National Institute of Technology, Jamshedpur, Jharkhand, India in 2000. Presently, he is working as Assistant Professor in Faculty of Engineering and Technology, Mody, Institute of Technology and Science (Deemed University) at Laxmangarh, Sikar(Rajasthan), India. $\mathrm{He}$ is Associate member of Institution of Engineers, India (AMIE) and Life member of ISTE. His area of interests includes Power systems, Network analysis, Control Systems, and Model Order Reduction of large scale systems.

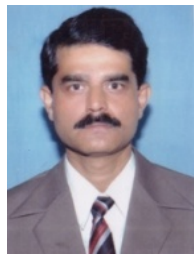

Dr. P. K. Ghosh was born in Kolkata, India in 1964. He received his B.Sc (Hons in Physics), B.Tech and M.Tech degrees in 1986, 1989, and 1991, respectively from Calcutta University. He earned Ph.D.(Tech) degree in Radio Physics and Electronics in 1997 from the same University. He served various institutions, namely, National Institute of Science and Technology (Orissa), St. Xavier's College (Kolkata), Murshidabad College of Engineering and Technology (West Bengal), R. D. Engineering College (Uttar Pradesh) and Kalyani Government Engineering College (West Bengal) before he joins Mody Institute of Technology and Science (Rajasthan). He is life member of Indian Society for Technical Education (ISTE), New Delhi. His research interests are in the areas of reduced order modeling, VLSI circuits and devices and wireless communications.

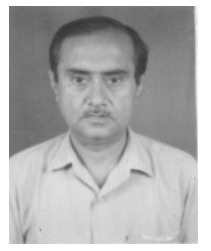

Dr. Shaktidev Mukherjee was born in Patna, India, in 1948. He received B.Sc. (Engg.) Electrical from Patna University in 1968 and M.E., Ph.D. from the University of Roorkee in 1977 and 1989, respectively. After working in industries till 1973, he joined teaching and taught in different academic institutions. $\mathrm{He}$ is the former Vice-Chancellor of Mody Institute of Technology and Science, (Deemed University), Lakshmangarh, Sikar (Rajasthan), India. Presently, he is Professor in the Department of Electrical Engineering at Indian Institute of Technology, Roorkee ,India. He is a life member of Systems Society of India (LMSSI). His research interests are in the areas of Model Order Reduction and Process Instrumentation and Control. 